\title{
Floral variation in Saxifraga granulata: phenotypic selection, quantitative genetics and predicted response to selection
}

\author{
STEFAN ANDERSSON \\ Department of Systematic Botany, University of Lund,Ö Vallgatan 18-20, S-22361 Lund, Sweden
}

\begin{abstract}
Plants of Saxifraga granulata, derived from a factorial crossing experiment, were raised under seminatural conditions (garden) to determine whether style morphology and other floral traits were heritable and correlated with female pollination efficiency (seed-set per flower). Differences between paternal half-sib families were statistically significant for most characters with low to moderate narrow-sense heritabilities for flower number, flowering date, plant height, petal size, stamen length and seed-set $\left(h^{2}=0.03-0.54\right)$ and high heritabilities for style length and stigma size $\left(h^{2}>0.75\right)$. In addition to a major trend contrasting early flowering, tall, manyflowered genotypes with large flowers and those with the opposite features, there was a strong negative genetic correlation between stamen length and stigma size. Seed-set per flower was highest for early flowering plants with many flowers, tall stems and large stigmas, and increased by 120 per cent after hand-pollination. Only flowering date had a direct effect on seed-set, whereas other traits were associated with seed-set through general plant vigour. Genetic responses predicted from selection coefficients, heritabilities and genetic correlations indicated a shift towards increased plant height, flower number, style length and stigma size and earlier flowering date.
\end{abstract}

Keywords: floral morphology, genetic correlation, heritability, natural selection, Saxifraga granulata

\section{Introduction}

Floral characters can evolve by natural selection when there is genetic variation in traits associated with pollination, the amount of response depending on the strength of selection, the heritability and the pattern of correlation between characters (Falconer, 1981). However, despite evidence that pollinators can act as a selective agent in natural plant populations (e.g. Campbell, 1989; Schemske \& Horvitz, 1989), there have been few efforts to establish whether heritable differences in floral characters can be expressed and influence pollination success under natural or seminatural conditions (Mazer \& Schick, 1991; Andersson \& Widén, 1993; Campbell et al., 1994; Young et al., 1994).

Numerous authors have demonstrated a selective advantage of structures attracting pollinators (e.g. Bell, 1985), but there is also strong evidence for selection on traits affecting the effectiveness per visit. For instance, the amount of pollen deposited per stigma generally increases with the degree of stigma exsertion (Thomson \& Stratton, 1985; Camp- bell, 1989; Motten \& Antonovics, 1992), presumably because more exserted stigmas increase the frequency with which the pollinators contact the stigma (but see Campbell et al., 1994). No attempt has been made to test the supposition that the rate of pollen receipt increases with stigma size, and little information is available on the genetic architecture of traits reflecting the size of the receptive surface (Robertson et al., 1994).

Vegetatively large plants tend to produce larger flowers than smaller individuals (Primack, 1987). Such associations can influence the heritability for floral morphology and other traits expressed late in the ontogeny. If vegetative size is determined by growth conditions, environmental heterogeneity is expected to obscure the expression of heritable floral variation, thereby slowing the evolutionary response to selection. Conversely, if plant size has a strong heritable component, then floral traits would automatically show genetic variation, leading to high heritabilities for these characters. Quantitative genetic analyses of data adjusted for overall plant size provide an opportunity to determine whether 
genetic variation in floral traits is caused by genes expressed during flower development or genes influencing plant size (Robertson et al., 1994).

In the study presented here, I examine whether there is a potential for pollinator-mediated selection in the perennial herb Saxifraga granulata using paternal half-sib families exposed to near-natural conditions. Particular attention was given to characters directly related to pollen receipt, but other traits were also considered. The following questions were addressed. Do differences in style length and stigma size translate into differences in female fertility, or is selection stronger on other characters? Is there genetic variation for floral traits and is this variation independent of differences in general plant vigour? To what extent are different floral traits genetically correlated? Would the effects of selection be passed on to the next generation as an evolutionary response?

\section{Materials and methods}

\section{Plant material}

The perennial herb Saxifraga granulata L. (Saxifragaceae) occurs in dry, calcareous grassland (west Eurasia, north Africa) and flowers from May to June, when plants develop a variable number of stems from basal rosettes with petiolate leaves and axillary bulbils. Flowering is determinate, starting with the flower terminating the stem and ending with flowers on the lowermost branches. Each flower has five white petals, 10 stamens and a gynoecium with two carpels fused at the base, each containing c. 250 ovules. Nectar is produced at the base of the ovary which develops into a capsule. The selfcompatible flowers are protandrous, the stigmas becoming receptive one or two days after the male phase. Some populations are gynodioecious, with female plants having smaller petals than hermaphrodites. Plants of $S$. granulata are visited by a wide variety of unspecialized insects, e.g. flies and solitary bees (Marsden-Jones \& Turrill, 1947; Tutin et al., 1976; Lindgaard Hansen \& Molau, 1994).

The plant material used in the present study is derived from a dry, ungrazed meadow c. $300 \mathrm{~m}$ east of Lockarp in SW Scania, the southernmost province of Sweden.

\section{Experimental procedures}

A factorial crossing experiment (North Carolina Design II, Comstock \& Robinson, 1952) was performed to assess patterns of (co)variation in floral characters. Prior to flowering in 1991, I transplanted spatially separated $(>30 \mathrm{~cm})$ leaf rosettes from the field site to pots in a greenhouse, a procedure that synchronized flowering. I assigned nine plants as pollen donors and five plants as pollen recipients, emasculated $c .15$ flowers per recipient and mated each donor to each of the recipients. After $c .3$ weeks, the seeds were collected and stored in paper envelopes. One pollen recipient failed to set seed in all crosses and was therefore discarded, resulting in a total of 36 full-sib families (9 donors $\times 4$ recipents).

In November 1991, I planted 3 seedlings per fullsib family in random positions in each of 10 plastic trays consisting of 144 square pots $(3.5 \times 3.5 \mathrm{~cm})$ with sandy soil. In April 1992, I arranged the trays in a completely randomized design in a sunny position of the Botanical garden of Lund, Sweden. In August 1992 , the plants were planted in slightly larger pots $(5 \mathrm{~cm}$ wide) and assigned to new random positions in the garden. The plants were watered to avoid mortality during early summer droughts but no fertilizer was provided.

All measurements were obtained in the summers of 1994 and 1995. In 1994, I recorded the date of flowering (number of days since 1 April), determined the maximum plant height $(\mathrm{mm})$ and counted the flowers produced by each plant. One flower on each plant was preserved in 70 per cent ethanol and measured under a dissecting microscope to obtain data on petal length, petal width, stamen length, style length and stigma width (one measurement per flower; mm). In 1995, I determined flowering date, plant height, flower number, style length and stigma width. Stigma width (hereafter 'stigma size') is linearly related to stigma area $(r=0.95, n=112$, $P<0.001$ ), as shown by a separate data set obtained with a video camera and image analysis software developed for Macintosh computers (IMAGEGRABBER $^{\text {TM }}$, OPTILAB ${ }^{\text {TM }}$ ).

Phenotypic data from 1995 were combined with estimates of seed-set to establish whether the floral traits influenced the amount of pollination achieved. I emasculated one flower on each plant to ensure that the seeds produced by these flowers were a result of cross-pollination. A month later, I collected the capsules, spread the seeds in each capsule on a Petri dish, employed the image analysis system to determine the area covered by the seeds on the video image, and then converted seed area to seed number using a predictive equation generated from a separate data set (seed number $=-3.99+0.556$ seed area, $r=0.99, n=20, P<0.001)$. To confirm that female fertility was pollen-limited, I estimated 
the seed-set of one hand-pollinated flower on each of 60 plants chosen at random from the experimental population. The hand-pollinated flower was situated on a branch adjacent to that from which the open-pollinated flower was collected. The outcross pollen came from one or two other nonsib plants.

Estimates of flower number and seed-set were log transformed (base 10) to meet normality and homoscedasticity assumptions in parametric analyses.

\section{Data analysis}

Two-way analysis of variance with pollen donor and pollen recipient as random factors, were carried out with the GLM procedure in sAS (type III sum of squares, SAS, 1985) to determine whether differences between paternal half-sibships (sires) were statistically significant. These analyses were followed by restricted maximum likelihood procedures (using the REML option in SAS PROC VARCOMP) to partition the total phenotypic variance $\left(V_{\text {total }}\right)$ into variance attributable to sire $\left(\sigma_{\text {sire }}^{2}\right)$, dam, the interaction between sire and dam and within-family variation. Assuming that the sire component estimates $1 / 4$ of the additive genetic variance $\left(V_{\mathrm{A}}=4 \sigma_{\text {sire }}^{2}\right)$ without confounding effects of nonadditive and nongenetic variation (Falconer, 1981), I calculated the narrowsense heritability $\left(h^{2}=V_{\mathrm{A}} / V_{\text {total }}\right)$ for the original variables and for the residuals of the floral traits when the effect of flower number had been removed (linear regression). Given the larger number of male parents, I considered the estimates of genetic variance from the male arrays to be more accurate than those from the female arrays. Other methods of estimating the genetic variation (Houle, 1992) provided little additional insight (data not shown).

Pearson correlation coefficients $(r)$ using paternal half-sib means (averaged across dam means) were calculated to estimate the additive genetic correlation between different characters (Falconer, 1981). The large number offspring per half-sib family $(n>48)$ should reduce the bias caused by family mean correlations containing fractions of the withinfamily component (Via, 1984). Correlation coefficients were also calculated to establish the phenotypic association between pairs of variables, whereas standardized partial regression coefficients from multiple regression expressed the direct effect of a character on seed-set (Lande \& Arnold, 1983).

Finally, I calculated the expected shift in each trait mean $(z)$ following a single generation of selection (Lande, 1979):

$\Delta z_{1}=b_{1} h_{1}^{2}+b_{2} h_{2} h_{1} r_{21}+\ldots+b_{5} h_{5} h_{1} r_{51}$,

(C) The Genetical Society of Great Britain, Heredity, 77, 217-223. where $b_{1} h_{1}{ }^{2}$ refers to the direct effect of selection on a trait (1) and the remaining terms refer to the indirect effect of selection on correlated traits (2-5). $b_{1-5}$ are the partial regression coefficients of relative fitness on the standardized values of the five characters measured in 1995, $h$ is the square root of the heritability, and $r$ is the genetic correlation between two traits. Relative fitness is the ratio of seed-set per flower or the estimated fecundity of each plant (seed-set per flower $\times$ flower number) to mean seed number. Separate analyses were carried out for genetic data obtained in 1994 and 1995.

\section{Results}

\section{Phenotypic variation}

Sixty-five percent of the seedlings (706 of 1080 plants) survived to 1994. Measurements of individual plants were moderately, but highly significantly correlated between 1994 and $1995(P<0.001)$, with the highest values for style length $(r=0.63)$ and stigma size $(r=0.67)$. Inspection of means (Table 1$)$ and paired $t$-tests indicated later flowering, more flowers per plant, taller stems, longer styles and smaller stigmas $(P<0.05-0.001)$ in 1995 than in 1994.

Four full-sib families (derived from a single pollen recipient) showed segregation for male sterility, but the total number of female offspring was small (13 of 580 plants in 1994; 18 of 565 plants in 1995). Female plants measured in 1994 flowered later and had smaller petals, shorter stamens and styles, and larger stigmas than hermaphrodites $(P<0.01-0.001$, $t$-tests). Corresponding analyses of traits measured in 1995 confirmed these results (not shown) and revealed a tendency for females to mature fewer seeds per capsule than hermaphrodites $(P<0.05$, $t$-test).

\section{Genetic variation}

Differences between paternal half-sibships were significant for almost all variables $(P<0.05-0.001$, two-way ANOVA), the exceptions being flower number and seed-set in $1995(P>0.05)$. The heritabilities (Table 1 ) were higher for style length and stigma size $\left(h^{2}>0.75\right)$ than for the other traits $\left(h^{2}=0.03-0.54\right)$, with a trend towards higher values in 1994 than in 1995. Adjusting for flower number had no consistent effect on heritabilities estimated in 1994, but resulted in higher estimates in 1995. Heritabilities changed by less than 0.03 when the 
females were excluded from the analyses (not shown).

\section{Patterns of correlation}

The phenotypic correlations (Table 2) contrasted early flowering plants with many flowers, tall stems,

Table 1 Means and narrow-sense heritabilities for Saxifraga granulata $\left(h^{2}\right) \cdot h_{\text {adj }}^{2}$ is for data adjusted for flower number. Significance levels refer to the $F$-value for the sire effect in factorial ANOVA

\begin{tabular}{lclc}
\hline Character & Mean & $h^{2}$ & $h_{\text {adj }}^{2}$ \\
\cline { 4 - 5 } l994 & & & \\
Flower number & 12.3 & $0.11^{*}$ & - \\
Flowering date & 38.0 & $0.41^{* * *}$ & $0.54^{* * *}$ \\
Plant height & 111 & $0.42^{* * *}$ & $0.33^{* * *}$ \\
Petal length & 12.2 & $0.26^{* *}$ & $0.27^{* *}$ \\
Petal width & 5.28 & $0.34^{* * *}$ & $0.32^{* *}$ \\
Stamen length & 5.58 & $0.54^{* * *}$ & $0.54^{* * *}$ \\
Style length & 3.90 & $0.98^{* * *}$ & $0.94^{* * *}$ \\
Stigma size & 1.40 & $0.88^{* * *}$ & $0.97^{* * *}$ \\
l995 & & & \\
Flower number & 12.6 & 0.03 & - \\
Flowering date & 39.3 & $0.24^{* * *}$ & $0.36^{* * *}$ \\
Plant height & 116 & $0.24^{* *}$ & $0.27^{* *}$ \\
Style length & 4.00 & $0.75^{* * *}$ & $0.76^{* * *}$ \\
Stigma size & 1.26 & $0.94^{* * *}$ & $1.00^{* * *}$ \\
Seeds/capsule & 117 & 0.10 & $0.18^{* *}$ \\
\hline
\end{tabular}

Measurements in $\mathrm{mm}$.

${ }^{*} P \leqslant 0.05,{ }^{* *} P \leqslant 0.01,{ }^{* * *} P \leqslant 0.001$. large petals, long stamens, exserted styles and large stigmas, from plants with the opposite features. Stigma size showed a weak, but significant negative correlation with stamen length and differed from style length in being more strongly correlated with flower number and plant height than with petal and stamen length. Patterns of correlations between paternal half-sib groups were similar to those based on individual plants (Table 2). There was a strong negative genetic correlation between stamen length and stigma size $(r=-0.82)$.

\section{Floral phenotype and seed-set}

The number of seeds per capsule averaged 117 ( $\mathrm{SD}=104, n=532$ ) for naturally pollinated flowers and $258(\mathrm{SD}=105, n=58)$ for flowers outcrossed by hand, a highly significant difference $\left(t_{57}=-5.4\right.$, $P<0.001$, paired $t$-test).

Many-flowered, early flowering and tall plants with large stigmas produced more seeds per capsule than plants with the opposite characters, whereas seed-set varied independently of style length (Table 3). Similar results were obtained in the regression analysis, although the positive relationship with flower number disappeared when other characters were held constant. Correlation and regression coefficients were larger for the hand-pollinated flowers, the only exception being flowering date which showed the opposite pattern. Inclusion of quadratic terms in analyses of open-pollinated flowers had little effect on the amount of variation

Table 2 Correlations between characters measured on Saxifraga granulata in 1994. The upper value is the phenotypic correlation $(n=577-581)$ and the lower value is the paternal half-sib mean correlation $(n=9)$. The significance of each correlation coefficient was tested using the $t$-test

\begin{tabular}{|c|c|c|c|c|c|c|c|}
\hline Character & 1 & 2 & 3 & 4 & 5 & 6 & 7 \\
\hline 1 Flower number & - & & & & & & \\
\hline \multirow[t]{2}{*}{2 Flowering date } & $-0.53^{* * *}$ & - & & & & & \\
\hline & -0.35 & - & & & & & \\
\hline \multirow[t]{2}{*}{3 Plant height } & $0.66^{* * *}$ & $-0.32 * * *$ & - & & & & \\
\hline & $0.92^{* * *}$ & -0.31 & - & & & & \\
\hline \multirow[t]{2}{*}{4 Petal length } & 0.01 & 0.03 & $0.22 * * *$ & - & & & \\
\hline & 0.20 & $-0.67^{*}$ & 0.12 & - & & & \\
\hline \multirow[t]{2}{*}{5 Petal width } & $0.12 * *$ & $-0.14^{* *}$ & $0.19 * * *$ & $0.35^{* * *}$ & - & & \\
\hline & 0.40 & $-0.75^{*}$ & 0.32 & 0.61 & - & & \\
\hline \multirow[t]{2}{*}{6 Stamen length } & -0.01 & $-0.10^{*}$ & $0.09^{*}$ & $0.40 * * *$ & $0.16^{* * *}$ & - & \\
\hline & -0.11 & -0.40 & -0.32 & 0.41 & 0.09 & - & \\
\hline 7 Style length & $\begin{array}{l}0.22^{* * *} \\
0.59\end{array}$ & $\begin{array}{l}-0.12^{* *} \\
-0.68^{*}\end{array}$ & $0.38^{* * *}$ & $\begin{array}{l}0.43 * * * \\
0.86 * *\end{array}$ & $0.21^{* * *}$ & $0.34 * * *$ & - \\
\hline \multirow[t]{2}{*}{8 Stigma size } & $0.42 * * *$ & $\begin{array}{l}-0.08 \\
-0.08\end{array}$ & $\begin{array}{l}\text { U.55 } \\
0.42^{* * *}\end{array}$ & $\begin{array}{l}0.86^{* *} \\
0.07\end{array}$ & $\begin{array}{l}0.50 \\
0.22^{* * *}\end{array}$ & $\begin{array}{c}0.32 \\
-0.21 * * *\end{array}$ & $0 . \overline{22} * * *$ \\
\hline & 0.36 & 0.42 & 0.46 & -0.23 & -0.06 & $-0.82^{* *}$ & -0.07 \\
\hline
\end{tabular}

${ }^{*} P \leqslant 0.05,{ }^{* *} P \leqslant 0.01,{ }^{* * *} P \leqslant 0.001$. 
Table 3 The relationship in Saxifraga granulata between seed-set and other characters, as revealed by the productmoment correlation coefficient $(r)$ and the standardized partial regression coefficient from multiple regression analyses $(b)$

\begin{tabular}{lccccrr}
\hline & \multicolumn{2}{c}{ Natural pollination $^{\mathrm{a}}$} & & \multicolumn{2}{c}{ Hand pollination $^{\mathrm{b}}$} \\
\cline { 2 - 3 } \cline { 5 - 6 } Character & $r$ & \multicolumn{2}{c}{$b$} & & $r$ & \multicolumn{1}{c}{$b$} \\
\hline Flower number & $0.35^{* * *}$ & $0.02 \mathrm{NS}$ & & $0.43^{* * *}$ & $0.08 \mathrm{NS}$ \\
Flowering date & $-0.46^{* * *}$ & $-0.41^{* * *}$ & $-0.25 \mathrm{NS}$ & $-0.15 \mathrm{NS}$ \\
Plant height & $0.32^{* * *}$ & $0.20^{* * *}$ & & $0.55^{* * *}$ & $0.49^{* * *}$ \\
Style length & $0.04 \mathrm{NS}$ & $-0.07 \mathrm{NS}$ & & $0.08 \mathrm{NS}$ & $-0.13 \mathrm{NS}$ \\
Stigma size & $0.17^{* * *}$ & $0.13^{* *}$ & & $0.30^{*}$ & $0.18 \mathrm{NS}$ \\
\hline
\end{tabular}

${ }^{*} P \leqslant 0.05,{ }^{* *} P \leqslant 0.01, P \leqslant 0.001$.

${ }^{\mathrm{a}} n=530-532$.

$b_{n}=56-58$.

Table 4 Predicted evolutionary response to selection through female function in Saxifraga granulata. Values are the expected shift in each trait mean calculated from selection coefficients and quantitative genetic data obtained in 1994 (I) or 1995 (II)

\begin{tabular}{lccccc}
\hline & \multicolumn{4}{c}{ Measure of fitness } \\
\cline { 2 - 3 } & \multicolumn{2}{c}{ Seed-set per flower } & & \multicolumn{2}{c}{ Seed-set per plant } \\
\cline { 2 - 3 } \cline { 5 - 6 } Character & I & II & I & II \\
\hline Flower number & +0.064 & +0.014 & +0.119 & +0.031 \\
Flowering date & -0.071 & -0.045 & -0.097 & -0.038 \\
Plant height & +0.140 & +0.082 & +0.227 & +0.092 \\
Style length & +0.107 & +0.075 & +0.204 & +0.064 \\
Stigma size & +0.118 & +0.099 & +0.146 & +0.036 \\
\hline
\end{tabular}

Measurements in $\mathrm{mm}$.

explained by the regression model $\left(R^{2}\right.$ increased from 0.27 to 0.28 ) and none of the traits showed a significant nonlinear relationship with seed-set $(P>0.15)$.

\section{Predicted response to selection}

The expected shifts in the means indicate a change in the positive direction for all traits except flowering date, which changed in the negative direction (Table 4). This pattern was most pronounced when the fecundity of each plant was used as a measure of fitness and when genetic parameters were calculated from the 1994 data, but the trend was seen in all analyses, providing confidence in the overall pattern.

\section{Discussion}

\section{Phenotypic selection}

Seed-set of open-pollinated flowers was about 45 per cent of the number of seeds produced by hand-pollinated flowers, and it appears that female fertility was at least partly determined by the amount of pollen achieved, a necessary assumption when using seed-set as a surrogate for pollen receipt. However, despite pollen-limitation and the fact that most characters were correlated with seed-set, I found little evidence for pollinator-mediated selection. There was no significant relationship between style length and seed-set per flower regardless of whether or not the effects of other characters were partialled out. Moreover, stigma size was positively related to seed-set regardless of whether or not pollen was in excess, indicating that plants with large stigmas allocated more nutritive resources to ovule and/or seed development than those with small stigmas (see also Eckert \& Barrett, 1995). A similar interpretation applies to the positive correlation between seed-set and the two measures of plant size (flower number, plant height), whereas flowering date probably had a direct effect on seed number, as shown by the stronger negative association between these variables for open-pollinated flowers than for flowers pollinated by hand. Leaving aside flowering date, it seems that most of the relationship between the floral characters and seed-set was a correlated response to variation in general plant vigour. Selection for traits increasing the amount of physiological resources may be more important that selection for a higher pollination success.

\section{Genetic variation}

The present investigation demonstrates moderate narrow-sense heritabilites for plant height, flowering date, petal size and stamen length, and high levels of additive variation for stylar characters $\left(h^{2}>0.75\right)$. The heritability values are comparable in magnitude to those estimated for floral characters in other wild plant species (Mazer \& Schick, 1991; Conner \& Via, 1993; Widén \& Andersson, 1993; Campbell et al., 1994; Robertson et al., 1994; Young et al., 1994), although Robertson et al. (1994) detected little heritable variation for stigma (lobe) size in Mimulus guttatus. When combined with the significant paternal (genetic) effect on viability (data not shown) and the finding that almost all characters were correlated with female fertility, data available for $S$. granulata clearly indicate that further evolution is possible. 
High heritabilities do not rule out an environmental effect, as shown by the significant difference in average style length and stigma size between 1994 and 1995, and the relatively low between-year repeatability for most traits $(r<0.68)$. In fact, environmental variation probably had a cumulative effect in obscuring genetically based differences, given the tendency for heritabilities to be lower in 1995 than in 1994. Finally, comparison of paternal half-sibships revealed low narrow-sense heritabilities for flower and seed number, a result consistent with the elimination of inferior genotypes because of the past action of selection (Falconer, 1981) and the particularly high levels of environmental variance in traits directly related to fitness (Houle, 1992).

In $S$. granulata, the sire effect always remained significant after removing the influence of overall plant size (flower number). Furthermore, variance component analyses of the size-corrected residuals usually resulted in higher narrow-sense heritabilities than those estimated using 'unadjusted' data, especially in 1995. These findings coupled with similar results from analyses of data adjusted for plant height (unpublished), show that most of the differences between floral genotypes can be attributed to genes expressed during floral development and not solely to genetic factors influencing overall plant vigour (Robertson et al., 1994). However, it is still necessary to assume disomic inheritance, linkage equilibrium, and that the progenies are representative samples of the same noninbred reference population (Falconer, 1981). Inclusion of epistatic variance arising from polysomic inheritance represents a potential bias (Kempthorne, 1955), given the wide range of chromosome numbers recorded in $S$. granulata $(2 n=32-60$, Tutin et al., 1976), although relatively low values have been reported for plants in southernmost Sweden $(2 n=34-36$, Weimarck, 1963).

\section{Correlation structure and predicted response to selection}

Previous studies have documented genetic correlations between stylar characters and leaf size (Conner \& Via, 1993), flower size (Conner \& Via, 1993; Fenster \& Ritland, 1994), flowering date (Fenster \& Ritland, 1994) and the time spent by flowers in the pistillate phase (Campbell et al., 1994). In light of these findings, it becomes interesting to ask whether similar trait associations exist in $S$. granulata and whether the correlation structure is conducive to further adaptive change in floral morphology.
The correlation analyses indicate a major axis of variation distinguishing early flowering plants with tall stems, many flowers, large petals, long styles and large stigmas, from those with the opposite traits. Given the selective advantage of early flowering, a tall stem, many flowers and large stigmas (see above), and the assumption that pollinators preferentially visit plants with large attractive structures (Bell, 1985), it appears that the direction of selection and the sign of the correlations converge for most of the characters. Hence, it is not surprising that the predicted shifts in the trait means generally agree in direction with the signs of the selection coefficients. In the case of style length, the mean is expected to change as an indirect genetic response to selection on characters more strongly correlated with fitness.

The lack of adverse correlations between characters correlated with seed-set does not exclude the possibility that such trade-offs exist for other suites of traits. For instance, it may be difficult for selection to operate independently on stamen length and stigma size, given the negative genetic correlation between these traits apparent in the correlation analyses and in the comparison of plants with and without functional anthers. This association not only represents a possible constraint on changes in the bivariate mean, but may also explain why a large amount of additive genetic variation has been retained for stigma size and stamen length. Of course, genetically based trade-offs are just one of several mechanisms that might contribute to the maintenance of adaptive genetic variation. In $S$. granulata, there is a potential for vegetative propagation to maintain inferior genotypes produced by mutation or recombination.

\section{Acknowledgements}

Financial support was provided by the Swedish Natural Science Research Council.

\section{References}

ANDERSSON, S. AND WIDÉN, B. 1993. Pollinator-mediated selection on floral traits in a synthetic population of Senecio integrifolius (Asteraceae). Oikos, 66, 72-79.

BELL, G. 1985. On the function of flowers. Proc. R. Soc. B, 224, 223-265.

CAMPBELL, D. R. 1989. Measurements of selection in a hermaphroditic plant: variation in male and female pollination success. Evolution, 43, 318-334.

CAMPBELL, D. R., WASER, N. M. AND PRICE, M. V. 1994. Indirect selection of stigma position in Ipomopsis aggre- 
gata via a genetically correlated trait. Evolution, 48, $55-68$.

COMSTOCK, R. E. AND ROBINSON, H. F. 1952. Estimation of average dominance of genes. In: Gowen, J. W. (ed.) Heterosis, pp. 494-516. Iowa State College Press, Ames. CONNER, J. AND VIA, s. 1993. Patterns of phenotypic and genetic correlations among morphological and lifehistory traits in wild radish, Raphanus raphanistrum. Evolution, 47, 704-711.

ECKERT, C. G. AND BARRETT, s. C. H. 1995. Style morph ratios in tristylous Decodon verticillatus (Lythraceae): selection vs. historical contingency. Ecology, 76, 1051-1066.

FALCONER, D. s. 1981. Introduction to Quantitative Genetics, 2nd edn. Longman, Harlow, Essex.

FENSTER, C. B. AND RITLAND, K. 1994. Quantitative genetics of mating system divergence in the yellow monkeyflower species complex. Heredity, 73, 422-435.

HOULE, D. 1992. Comparing evolvability and variability of quantitative traits. Genetics, 130, 195-204.

KEMPTHORNE, O. 1955. The correlation between relatives in a single autotetraploid population. Genetics, 40, $168-174$.

LANDE, R. 1979. Quantitative genetic analysis of multivariate evolution, applied to brain:body size allometry. Evolution, 33, 402-416.

LANDE, R. AND ARNOLD, s. J. 1983. The measurement of selection on correlated characters. Evolution, 37, 1210-1226.

lindgaArd hansen, J. E. AND molau, u. 1994. Pollination biology, mating system, and seed set in a Danish population of Saxifraga granulata. Nord. J. Bot., 14, 257-268.

MARSDEN-JONES, E. M. AND TURRILL, w. B. 1947. A quantitative study of petal size and shape in Saxifraga granulata. J. Genet., 48, 206-218.

MAZER, S. J. AND SCHICK, c. T. 1991. Constancy of population parameters for life-history and floral traits in
Raphanus sativus L. II. Effects of planting density on phenotype and heritability estimates. Evolution, 45, 1888-1907.

MOTTEN, A. F. AND ANTONOVICS, J. 1992. Determinants of outcrossing rate in a predominantly self-fertilizing weed, Datura stramonium (Solanaceae). Am. J. Bot., 79, 419-427.

PRIMACK, R. B. 1987. Relationships among flowers, fruits, and seeds. Ann. Rev. Ecol. Syst., 18, 409-430.

ROBERTSON, A. W., DIAZ, A. AND MACNAIR, M. R. 1994. The quantitative genetics of floral characters in Mimulus guttatus. Heredity, 72, 300-311.

SAS. 1985. SAS User's Guide: Statistics. SAS Institute, Cary, NC.

SCHEMSKE, D. W. AND HORVITZ, c. C. 1989. Temporal variation in selection on a floral character. Evolution, 43, 461-465.

THOMSON, J. D. AND STRATTON, D. A. 1985. Floral morphology and cross-pollination in Erythronium grandiflorum (Liliaceae). Am. J. Bot., 72, 433-437.

TUTIN, T. G., HEYWOOD, V. H., BURGES, N. A., MOORE, D. M., VAlENTINE, D. H., WALTERS, S. M. AND WEBB, D. A. 1976. Flora Europaea, vol. 1. Cambridge University Press, Cambridge.

weimarck, H. 1963. Skånes Flora. Corona, Lund, Sweden. VIA, s. 1984. The quantitative genetics of polyphagy in an insect herbivore. II. Genetic correlations in larval performance within and among host plants. Evolution, 38, 896-905.

WIDÉN, B. AND ANDERSSON, s. 1993. Quantitative genetics of life-history and morphology in a rare plant, Senecio integrifolius. Heredity, 70, 503-514.

YOUNG, J. H., STANTON, M. L., ELLSTRAND, N. C. AND CLEGG, J. M. 1994. Temporal and spatial variation in heritability and genetic correlations among floral traits in Raphanus sativus, wild radish. Heredity, 73, 298-308. 